\title{
Revealing on Miao Witch culture-----Citing psychology to analysis Miao Witch Culture
}

\author{
Fei Wang \\ Wenshan University, Wenshan, 663000, China
}

Keywords: Miao witch culture, psychology, unconscious theory,non - association thinking

\begin{abstract}
Miao family make ancestor worship as the core, combined with natural worship, more god worship, totem worship and other primitive religion, and based on these primitive belief system, rich the birth of the Miao witch culture. In recent years, scholars have studied the Miao-witch culture has been fruitful. This paper first introduces the historical background of the Miao people, and gradually analyzes the common non - association thinking and Jung 's unconscious theory in the Miao' s witch culture from the literary creation, and further reveals the mystery of the Miao 's witch culture from the psychological level.
\end{abstract}

\section{Introdution}

Miao family is one of the longest ethnic minorities in the Chinese nation."Chi You Jiu Li" is the earliest ancestors of the Miao, its historical records can be traced back to 5000 years ago.Similarly, the Miao Witch Ghost cultural tradition can also be traced back to the primitive society.Miao Witch Ghost Culture has not only a long history, but also it involves a wide range.

When people cannot make a reasonable explanation of the fear of the unknown, the ghost theories slowly develop, but also people is fear of life and death and worship. Then some people claim to be able to control, know the power of ghosts, promote their own witch to meet the needs of people, this is the beginning of the twentieth language.

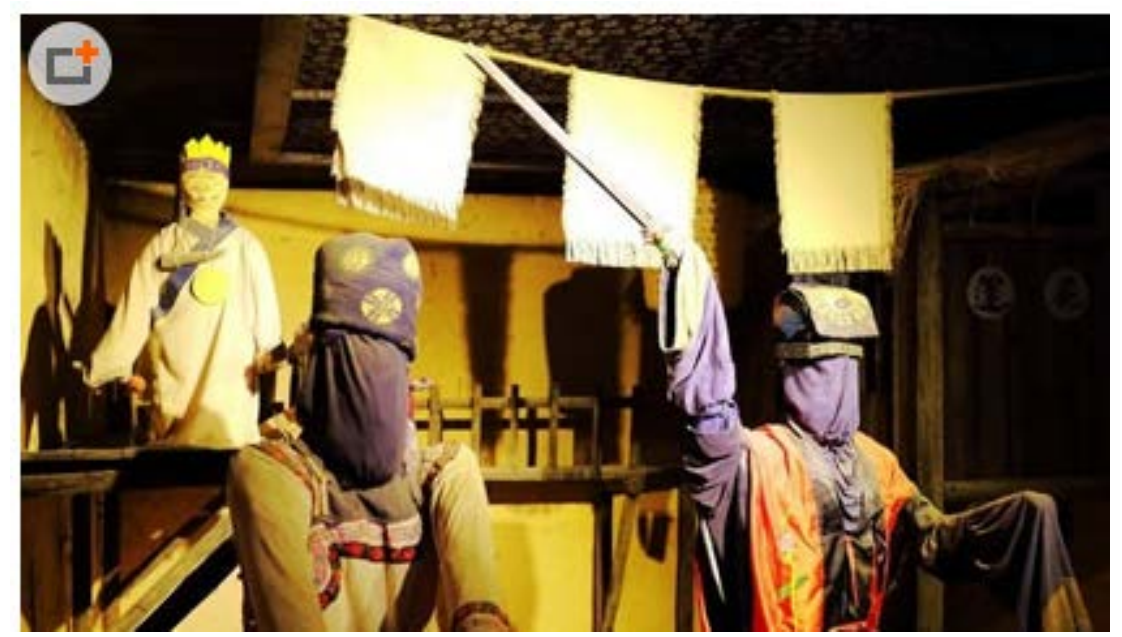

Fig.1 The Miao culture

Witch culture infiltrate in the northwest of the Miao production and life in all aspects from the beginning to the formation of the entire development process such as migration, war, festivals, and basic necessities. If they encounter natural disasters, they will pray disaster by witchcraft way.Miao first believe in spirits, worship witchcraft. Witch culture is the originator in the medical system, in the ancient Miao, the witch doctor is not divided. Originally the Miao has been found herbal medicine and acupuncture and other medical treatment in ancient times, but the medicine has been in the witchcraft mysterious veil under the cover. 
Miao people from birth to death are in a dense cultural atmosphere of the witch.For example, when the baby was born from the womb, a bowl is put his (her) bed, which is filled with rice, an egg is put on the rice. Its witchcraft meaning is the soul, exorcism, evil spirits, bless this young life from disaster.When the child grows up, aging, death, the shaman also sing "burn towel" to send the soul. First the shaman send its soul back to the East home, and then sent to the moon, let it complete this happy life journey, as he was alive, regardless of red and white happy event, basic necessities, or family changes, festivals, are closely related with the witch culture. Therefore, when people mention witch culture,they will think of the Miao witch culture.

There is an activity called "Miaojia rice", also known as "cauliflower God" in Miao famliy, the activities of the time in the lunar July to July half.In the light of the moonlight, people concentrated in the village side of the open, one or several people play "seven girls" fugue heaven.Wizards and all those who do "seven girls" know that some places, the fugue who can know where is a ditch, where is a dog, where is other thing, they can say clearly, If they encounter dead souls of their loved ones, such as the young men and women, they will make their antiphonal song. It is said that this is the result of the teachings of God (seven girls, etc.) that people who do not usually sing. Why do they have a specific song talent after entering a foolish state - a kind of inspiration that you cannot have when awake? This song is not "divine" it? The following will be analyzed one by one.

\section{The non-associated thinking on Miao Witch culture}

Miao's witch culture and the combination of non-related things are closely linked.The combination of non-related things is a basic form of non-association thinking.The so-called non-associated thinking is not unrelated thinking, otherwise there is no trace to find.Non-associative thinking puts two or several incompatible objects together and examines their identity.

Picasso once put a bicycle seat and a handlebar together, so there was a work of art - turned to shape. The bike's seat was not familiar with the form, but only Picasso saw the tacit understanding between them, he linked the two unrelated things, forming a new unity. It has been pointed out that this is a "magic of the integrated", but unfortunately a lot of people cannot think of this synthesis, it is a non-associated thinking, that is, non-related combination.

In the animated film "Mickey Mouse and Donald Duck", we see that non-associated thinking almost occupies the main position. The dog Brato was thrown out, sticking to the wall like a mud; the car was as panting like a beast, and shaking off the river when it was ashore. I think all kinds of changes in the demons and ghosts are out of this.

Non-associated thinking has no logic from apperence, in fact, it is also a logic, "similar to the same" is a kind of thinking clues. There are a lot of activities in the Miao witchculture, and its meaning is to let people know that the road of life is always rough and hard, but people do not worry about difficulties, do not be afraid, and they should have the determination to overcome difficulties, twists and turns of the road show a different kind of life, they should believe that the method is better than the problem, any difficulties can be overcome.

\section{Fantasy mix on Miao Witch culture}

In the combination of non-related objects, the bounds each retain a feature of the part. The "combination" can reveal the special significance of the relationship between the two sides, resulting in double association. When the incompatible things constitute a new unity, the two sides do not eliminate the opposition, but also in the confrontation state of each other, so that the thinking of the observer constantly under the influence of the three-dimensional feel.

Stirling's "Ghost Sonata" makes the corpses and living at the same time debut, shows the people of each other rolling, eyeing most vividly. Latin American "magic realism" break the magic and real, life and death, the boundaries of people and ghosts, novel characters can enter the nether world, can also enter the real world to live.

There are certain prerequisites for this type of "magical synthesis", and Latin American indigenous peoples have their own unique myths, legends, totems, witchcraft, religion, etc., which is the cultural 
realism of magical realism. Latin America has a very diverse and magical reality, in addition to jungle, wilderness, wilderness, valleys, crocodiles, pythons, carnivores and other horrible life, there are white culture and indigenous culture of the great contrast, which becme a magical realism of the cultural soil.

Garcia Marquez writer who won the Nobel Prize in Latin American wrote "a hundred years of loneliness", the critics believe that "deliberately innovation", "imagined rich", he thought it was derived from life. He said in the "guava fragrance" : "Perhaps my grandmother's story opened up a new way in her view to me, myths, legends, people's beliefs are the daily life of part. "

Miao people have "people first" philosophy, that the universe is all created by the ancestors, which will determine the eternal existence of human nature. Miao people think that death is the place to return to their ancestors. The wizards deliberately use the magic to send the soul, and can talk with the souls. The souls of the souls live happily in the grave, and always recite their children and grandchildren, who have the ability to transcend time and space that the living does not have. Therefore, the above mentioned "God" and "overcast" are commonplace, it is not surprising.

\section{The psychology on Miao Witch Culture}

From a psychological point of view, I think the kind of specific inspiration mentioned above is not divine, but his (her) own deep psychological activation and restlessness.Jung use unconscious theory to study the original consciousness and primitive human deep psychological, which have a direct reference value for our studying the psychological. He said the crazy, illusion, are the primitive" mind projection ", which like the mentally ill in the same mind. It is not the objective existence of the "gods", but the deep psychological unconscious projection of the illusion.

How does the projection and illusion of the mind produce? People in the wake of the senses accept external stimuli, causing the surface of the psychological activities. The psychological content of the surface is a reflection of reality. Deep psychological content is instinctive, is the collective representation of the times. Middle-level psychological content is forgotten concept and image.

Dream of the scene and the illusion of mental patients have three levels of heart content. People fall asleep, the cerebral cortex of the vast area was suppressed, but the individual excitement has not yet suppressed. Individual excitement of excitement or excitement caused by some excitement, the formation of phantom series is non-logical. This dream is "day thinking, night dream" dream, which is the aftermath of the surface consciousness.Middle of the dream of mental activity is the legacy of the past and forgotten content. Deep psychological dream, is not a personal experience of "race memory", "collective appearance", it is a symbol of the image, it does not express a fixed life content.

The wizard's mental activity is similar to the dream. If he needs to be mad to enter the spirit world, he has to use masked and other means to promote the inhibition of the cerebral cortex, or the use of spells and spiritual objectsnto play the role of witchcraft. In this way, the shaman's brain cortex slowly is inhibited and gradually coma, as if into sleep. He only heard the voice of the guide, the other did not know. Usually the surface of the psychological is active, deep psychological seems to be asleep, when he is crazy, the surface psychological is made suppression, the middle and deep psychological are activated, released, and thus inspired and exotic song talent.

The inspired by the psychological excitement is only the full potential of people to play, and the content is determined by his deep and middle of the psychological structure of the stored information.

\section{Conclusion}

Miao primitive religion as a Miao witch culture prototype, its spirits worship and witch culture quite original witch characteristics, which can be described as the original religion and its historical evolution of a rare model.

Witch culture originated in the early primitive society, the main carrier is witchcraft, the practice of "supernatural force" to influence the object or control is its main feature. There is generally full-time witchcraft, the wizards, who are considered to have this "supernatural force". In the northwest of Guizhou Miao nationality, witch culture is made infiltration of production, life, customs, etiquette, 
weddings and funerals, social interaction at all levels.

Miao's witch culture has its specific growth soil and self-contained way of thinking, in the psychological, it is the result of deep psychological restlessness. As we all know, the Miao is a nation without their own words, all of which are by mouth and ears - what makes these traditions and customs can go through thousands of years of history, witch Culture, love ancestors are the core of the Miao folk.

Everything has two sides. It plays a positive role at the same time in the daily life at the same time; it will inevitably have some negative effects. Miao witch culture make contradictory with the development of modern market economy.Miao witch culture bind people's creative thinking; it is not conducive to the development of productive forces.

Therefore, making the correct treatment of the Miao Witch culture and the correct analysis of the meaning and influence of the Miao-witch culture, which have great significance for the development of the Miao.

\section{References}

[1] Liang Tian. A Brief History of the Miao Nationality: Illustrated with Guizhou Ethnic Publishing House[J]. Journl of Wenshan University, 2006, 29(6): 88-93.

[2] Jungger Collection. Analyzing Original thinking [J].Journal of Beijing Normal University (Natural Science), 1981, 51(6): 643-648.

[3] Li Huailong. The Confirmation of Measurability: Epistemological Foundation ofPsychological and Educational Measurement [J]. Psychological Exploration, 2015, 35(4): 303-306.

[4] Su Aoxue. Principles of Literature [J]. Peking University Press (2004),: 43-47.

[5] Lu Daji. Religious theory of new [M]. China Social Science Press, 1998.

[6] Shi Qigui. Xiangxi Miao field investigation report [M]. Hunan People's Publishing House, 1985. 